\title{
Semi-Virtual laboratory design for photovoltaic generator characterization performance
}

\author{
Hocine Belmili ${ }^{1, *}$, Mourad Haddadi ${ }^{2,{ }^{* *}}$, Salah Med Aitcheikh ${ }^{2}$, Ahmed Chikouche $^{1}$ \\ ${ }^{1}$ Group of research: Photovoltaic system, Unit of Development of Solar Equipments (UDSE) \\ National road N: 11 Bou-Ismaïl LP 365, Tipaza 42415, Algiers, \\ ${ }^{2}$ Laboratory of communication devices and photovoltaic conversion (LCDPVC), Polytechnic National \\ School, 10 Avenue Hacen Badi El Harrach Algiers, \\ *belmilih@yahoo.fr ,**mourad_haddadi@yahoo.fr
}

\begin{abstract}
This paper present a study of the photovoltaic generator (PVG) performance. It basing on comparison between characterizations obtained in real time test and simulated ones using mathematical models. This study is evaluated by the design of a semi-virtual laboratory, which is composed on a hardware support based on the developed data acquisition system in real operating conditions and a software support based on mathematical models descriptions. T his laboratory permits to identify PVG parameters using correlation between measurements and simulated characteristics.
\end{abstract}

Keywords: Simulation, photovoltaic generator, characterization, performance, hardware, software.

\section{Introduction}

PVG or PV modules in general are formed by a co mbination of parallel and series connections of solar cells. The electrical characteristics of PV modules are rated at standard irradiance and temperature conditions. The standard conditions are AM1.5 spectrum, 1000 $\mathrm{W} / \mathrm{m} 2$ at $25^{\circ} \mathrm{C}$ cell temperature, for terrestrial applications, whereas for the extraterrestrial standard conditions it is AM0 $(1353 \mathrm{~W} / \mathrm{m} 2)$ at $25^{\circ} \mathrm{C}[1]$. Therefore the user knows only the electrical parameters nominal values of the PV module, which may be different from the values during the operating conditions. The variation of the characteristics from one set of conditions to another is a problem faced by designers and users, who want to know the outputs of a PV installation in real conditions rather than those given by the manufacturer in standard conditions [2]. Several environmental factors act to influence the performance of photovoltaic devices such as the temperature, the solar angle of incidence, the total irradiance level, the irradiance spectrum and optical effects due to shading. Numerous performance analysis studies have been carried out to assess the magnitudes of these effects, yet there is still some debate about the relative importance of each factor. Due to strong correlations between each environmental driver, their separation for quantification has proved a major challenge that has not yet been met conclusively [3]. Figure 1 represents the block diagram of the semi-virtual laboratory design.

\section{PVG model description}

There are several description models for PVG. Some themes are analytical models; the other ones are empirical and semi-empirical model. In this context we present two PVG model descriptions. The first one is an analytical model basing on one-diode model and the second one is an empirical model which is developed by Sandia Laboratory.

\subsection{One-diode PVG model}

One-diode model of PVG is presented as an electrical circuit as showing the figure 2. 


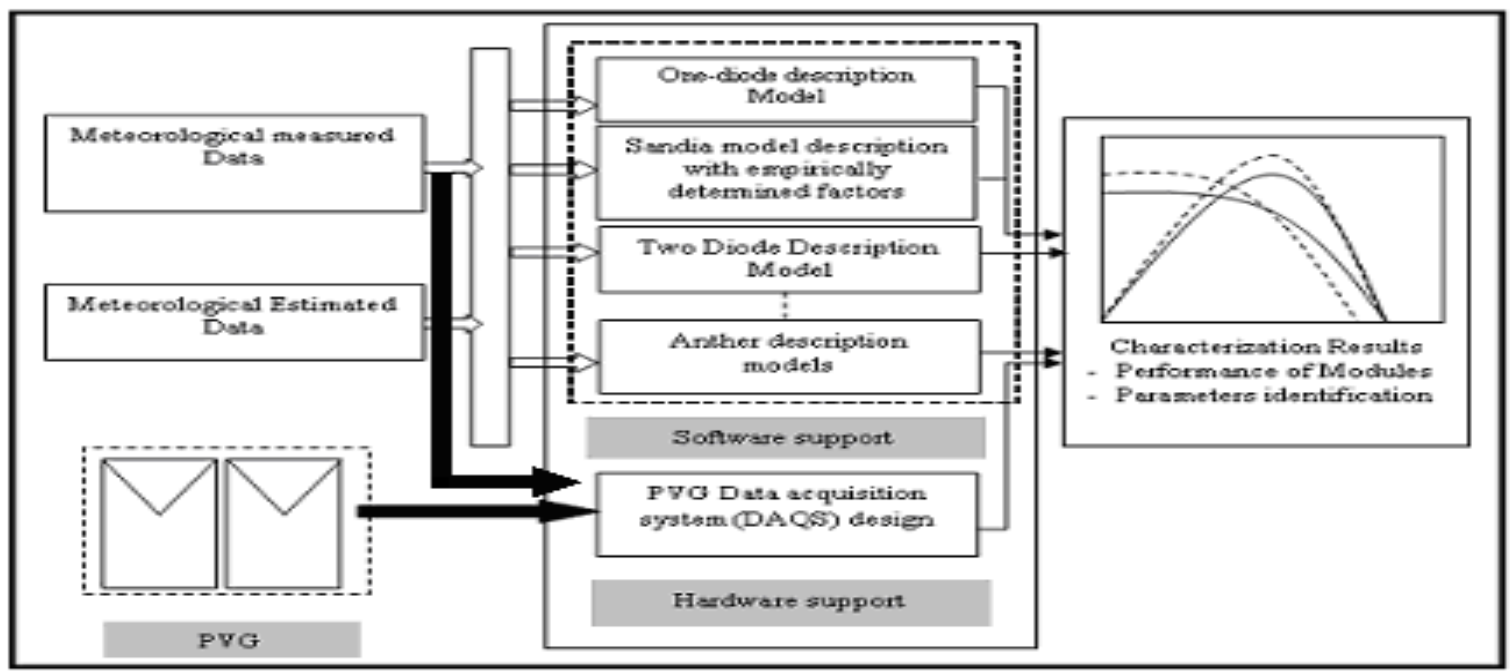

Fig.1: Semi-virtual laboratory design for PVG characterization performance.

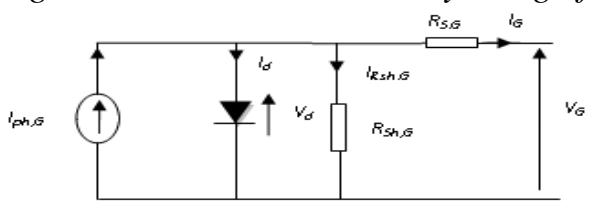

Fig. 2: one-diode equivalent circuit model.

At a fixed temperature and solar irradiation, the I-V curve of this circuit is given by equation:

$I_{G}=I_{p h, G}-I_{S}\left[\exp \left(\frac{q\left(V_{G}+R_{S, G} \cdot I_{G}\right)}{n n_{S} k T}\right)-1\right]-\frac{V_{G}+R_{S, G} \cdot I_{G}}{R_{S h, G}}$

The parameters for this model, described elsewhere [4], can be found by either numerical or analytical methods. It has been shown that the circuit parameters $I_{p h}, R_{s h}, R_{s}, I_{s}$ and the diode ideality factor ' $\mathrm{n}$ ' at a particular temperature and irradiation can be computed from the $V_{\text {oc }}$, $\mathrm{I}_{\mathrm{sc}}, \mathrm{V}_{\mathrm{m}}, \mathrm{I}_{\mathrm{m}}, \mathrm{R}_{\mathrm{so}}$ and $\mathrm{R}_{\text {sho }}$ values measured from the I-V characteristic. Several researchers have either investigated or developed numerical algorithms to determine the solar cells parameters by fitting measured I-V curves [5]. The difficulty to obtain the PV parameters, from the measured I-V curves, resides in the implementation of complex computer algorithms since the estimation of these parameters, somehow, are restricted to specific research laboratories as those studying fundamental physics device. However, analytical methods can be used as a design tool to derive the parameters from the basic data given by PV module manufacturers, or other readily available data. Under Simulink we present this model as following

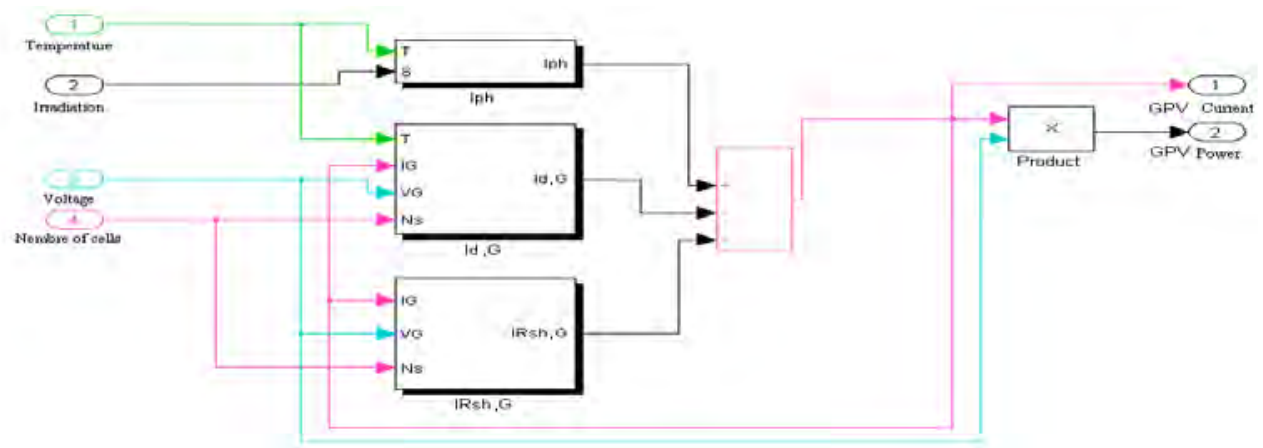


Fig.3: One-diode PVG model simulation under Simulink.

\subsection{SNL model description}

SNL (Sandia National Laboratory) performance model is an empirically based method. It achieves its versatility and accuracy from the fact that individual equations used in the model are derived from individual solar cell characteristics. The versatility and accuracy of the model has been demonstrated for different photovoltaic and concentrator modules, as well as for large arrays of modules. This model takes account of electrical, thermal, solar spectral and optical effects for photovoltaic modules [6]. The performance modeling approach has been well validated through extensive outdoor module testing, and through inter-comparison studies with other laboratories and testing organizations [7]. Recently, the performance model has also demonstrated its value during the experimental performance optimization of off-grid photovoltaic systems [8]. The following equations define the model used by the Solar Technologies Department at Sandia for the analysis and the modelling of the photovoltaic modules performances. The equations describe the electrical performances for individual photovoltaic cells, modules, and arrays. The solar resource and weather data required by the model can be obtained from tabulated databases [9] or from direct measurements.

$$
\left\{\begin{array}{l}
I_{s c}\left(E, T_{c}, A M_{a}, A O I\right)=\left(\frac{E}{E_{0}}\right) f_{1}\left(A M_{a}\right) \cdot f_{2}(A O I)\left\{1+\alpha_{\text {Isc }} \cdot\left(T_{c}-T_{0}\right)\right\} \\
E e=I\left(E, T_{c}=T_{0}, A M_{a}, A O I\right) / I_{s c 0} \\
V_{o c}\left(E_{e}, T_{c}\right)=V_{o c 0}+C_{3} \cdot \ln \left(E_{e}\right)+\beta_{V_{v}} \cdot\left(T_{c}-T\right. \\
V_{m p}\left(E_{e}, T_{c}\right)=V_{m p 0}+C_{4} \cdot \ln \left(E_{e}\right)+C_{s} \cdot\left\{\ln \left(E_{e}\right)\right\}^{2}+\beta_{V_{\text {mpp }}} \cdot\left(T_{c}-T_{0}\right) \\
I_{m}\left(E_{e a}, T_{c}\right)=C_{1}+E e\left\{C_{2}+\alpha_{I_{m p}} \cdot\left(T_{c}-T_{0}\right)\right\} \\
P_{m p}=I_{m p} \cdot V_{m p} \\
F F=P_{m p} /\left(I_{s c} \cdot V_{o c}\right)
\end{array}\right.
$$

The following figure represents Simulink simulation of this model.

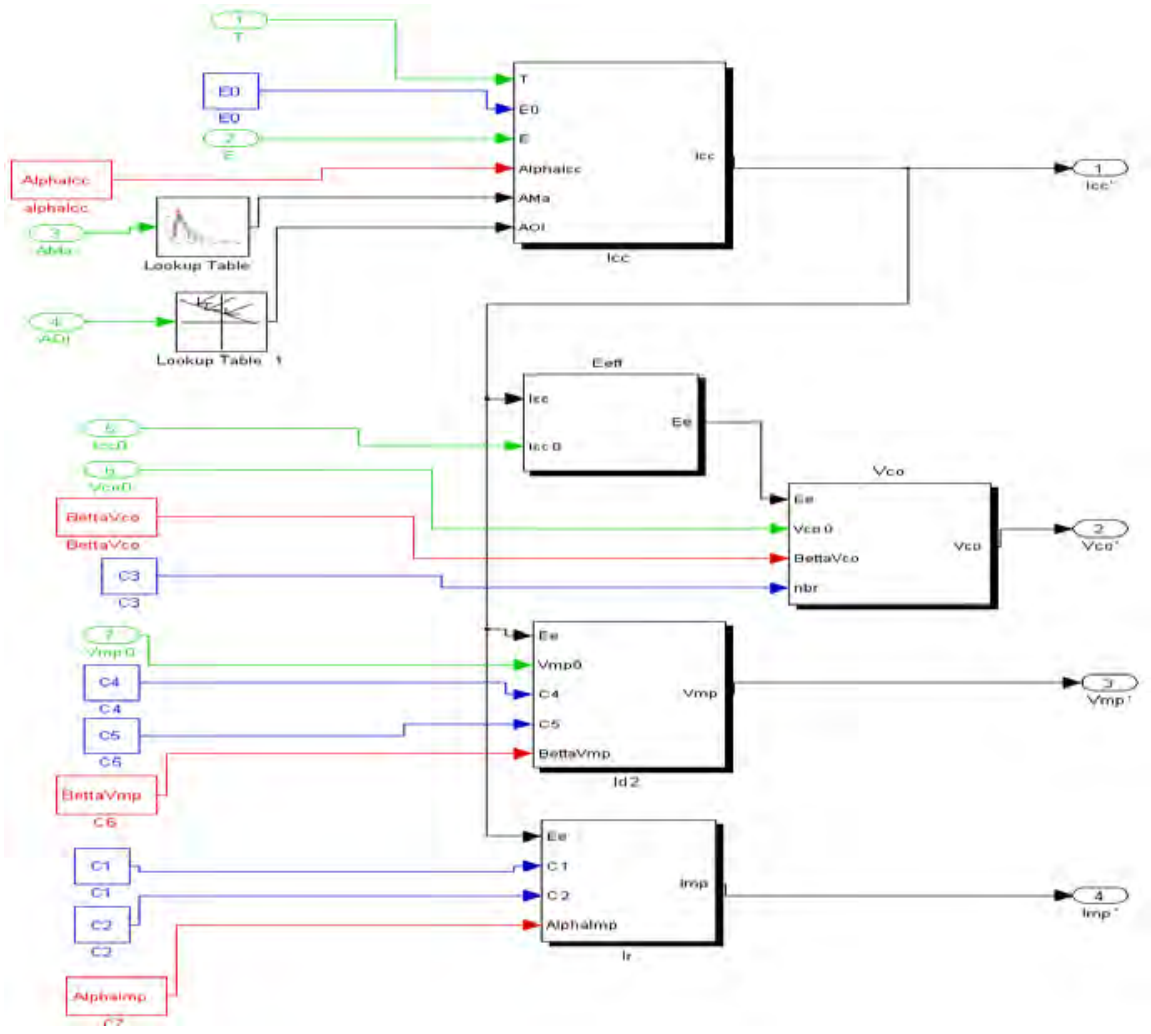


Fig.4: Sandia PVG model simulation under Simulink.

\section{Hardware design and development of a real-time PVG characterizer}

The Hardware part is based on a development of a data acquisition system for real time PVG characterization. $\mathrm{T}$ he data acquisition system (DAQS) is an important part of the experimental setup. A good experiment can be completely ruined if the data is not collected with the necessary precision and repetition. Figure 5, s hows the block diagram of the developed system. The DAQS is linked to a graphical user interface. The developed hardware parts basic element is the electronic load [10]. This electronic load can characterize an array of one or two solar modules connected in serial or in parallel, protected with a by-pass diode. Figure 5 show the block diagram of the developed hardware PVG testing unit.

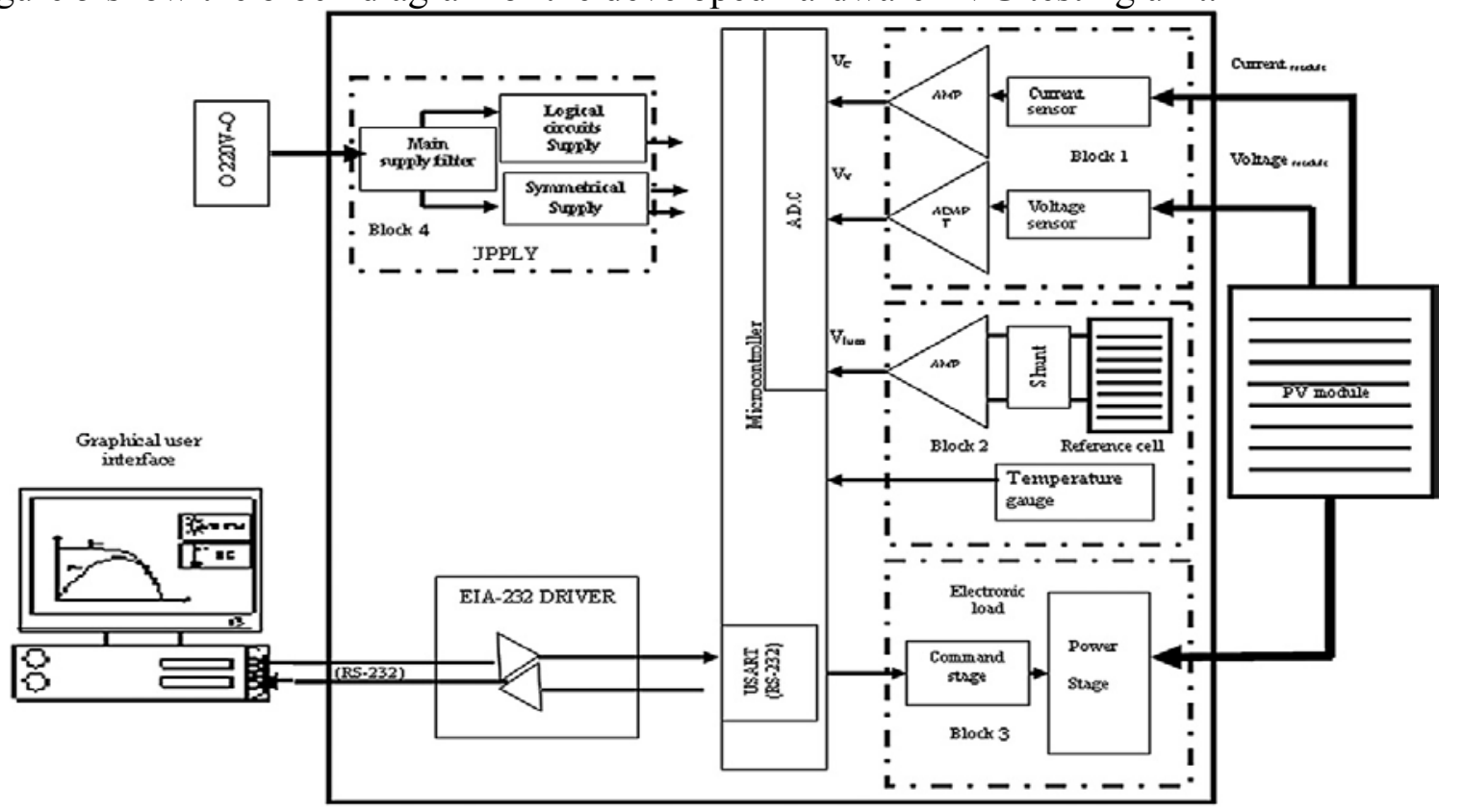

Fig.5: Block diagram of PVG testing unit.

\section{Software design}

The software has been developed using Object-Oriented Programming (O.O.P) under windows. This software based on the development of a three principal programs (figure 6). The first one to estimate irradiation on PVG captor, the second to extract PVG parameters from manufactures data sheet and from other temperature and irradiation inputs and the third one we permits to identify PVG parameters using correlation between measured and estimate characteristics.

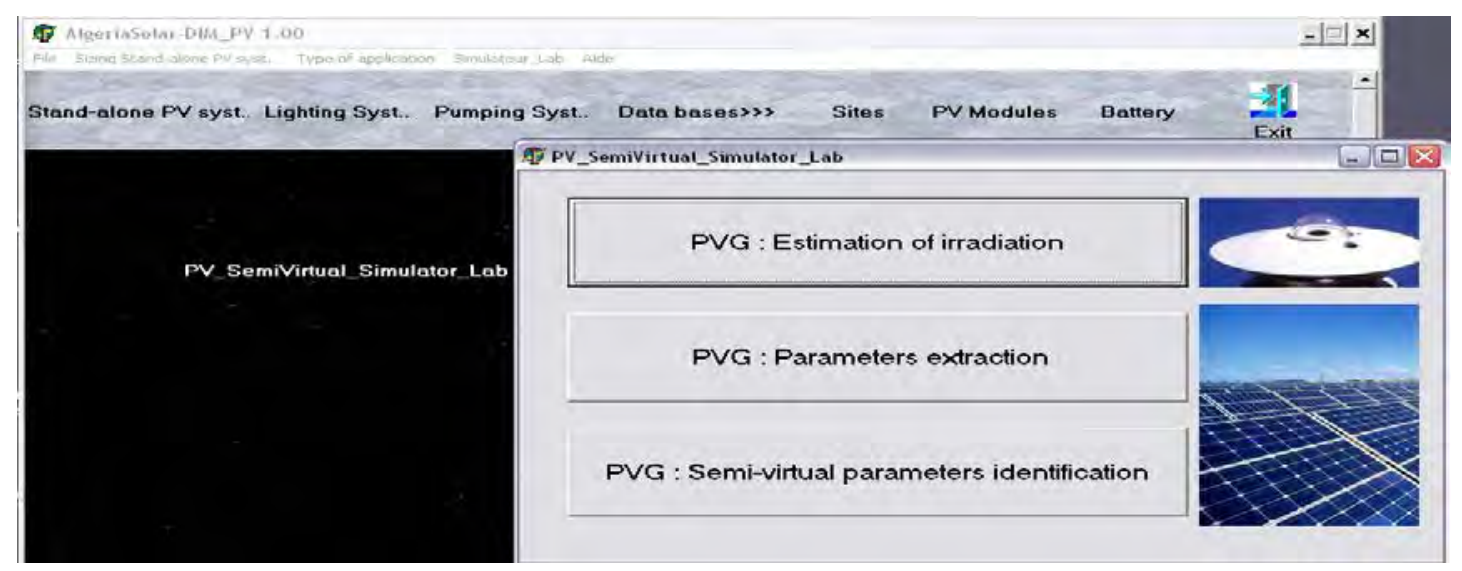


Fig. 6: software design.

\subsection{Estimated irradiation program}

In this context the developed software is based on a specific algorithm for irradiation simulation [11]. Figure 7 represent the input data window of the developed software for the daily and annual estimation irradiation for different locations. In the present window, sites are identified by the geographical location (latitude, longitude and altitude). With this program, we simulate global horizontal and inclined irradiation. The Albedo represents the diffusion coefficient. Its value belongs to $[0.1,0.9]$. The user introduces the year day number and the angle of incidence (AOI) of the irradiation on the module. This software has a data base of different sites in the word. The user can introduce other sites, not configured in the data base, by introducing its geographical location. He, then, can estimate the global and inclined, daily and annual irradiation of the introduced site. The daily sunshine duration is also calculated when the user start execution of daily irradiation simulation.

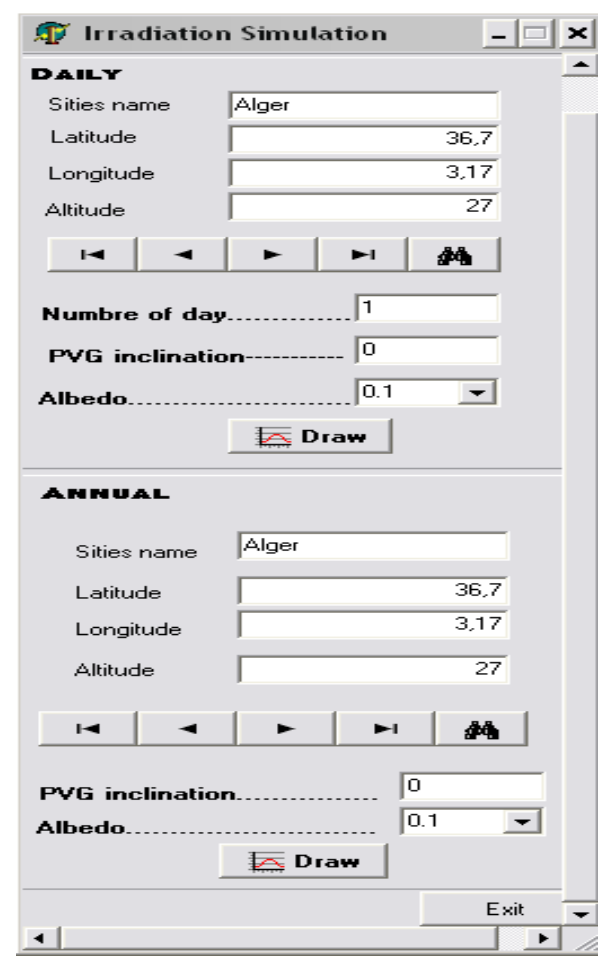

(a)

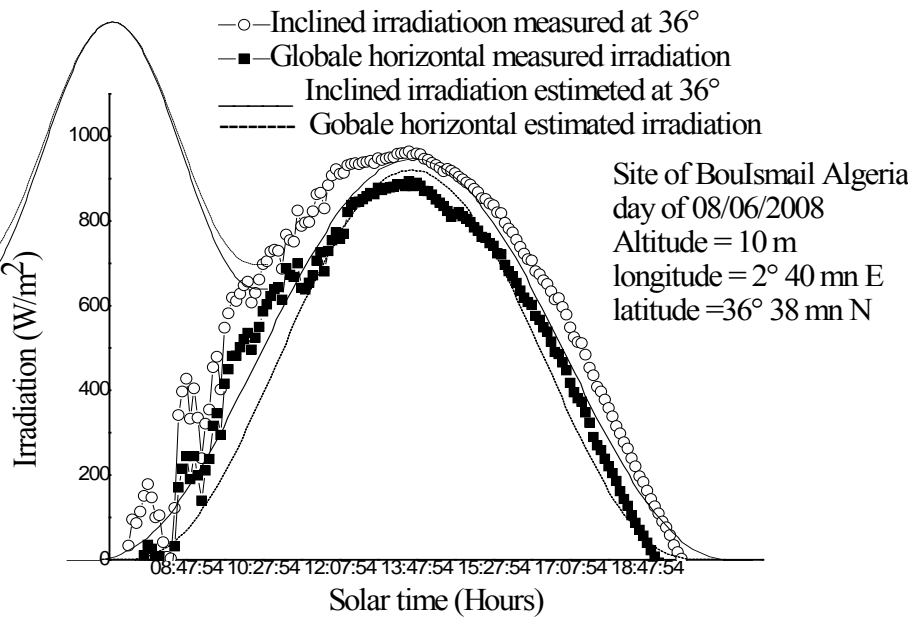

(b)

Fig. 7: (a) Inputs data (latitude, longitude and altitude) window for daily and yearly irradiation simulation for sites characterization, (b) Measured and estimated irradiation comparison results.

\subsection{Developed software for PVG Parameter extraction}

Figure $8 \mathrm{~s}$ hows the input/output data window for the PVG characterisation under STC conditions and under measured irradiation and temperature conditions. This software disposes of a u ser-friendly PV modules database for different manufacturers. Using one-diode description model for PV module, this program can identifying the five parameters models: ideal factor, serial resistance, shunt resistance, saturation current and photocurrent. The modules in the database are identified by the manufacturer reference and by their STC condition characteristics: Isc, Voc, Im, Vm and Pm. Besides, thru this software, we can add in the database other commercial modules and carry out their characterization, figure 8 . 


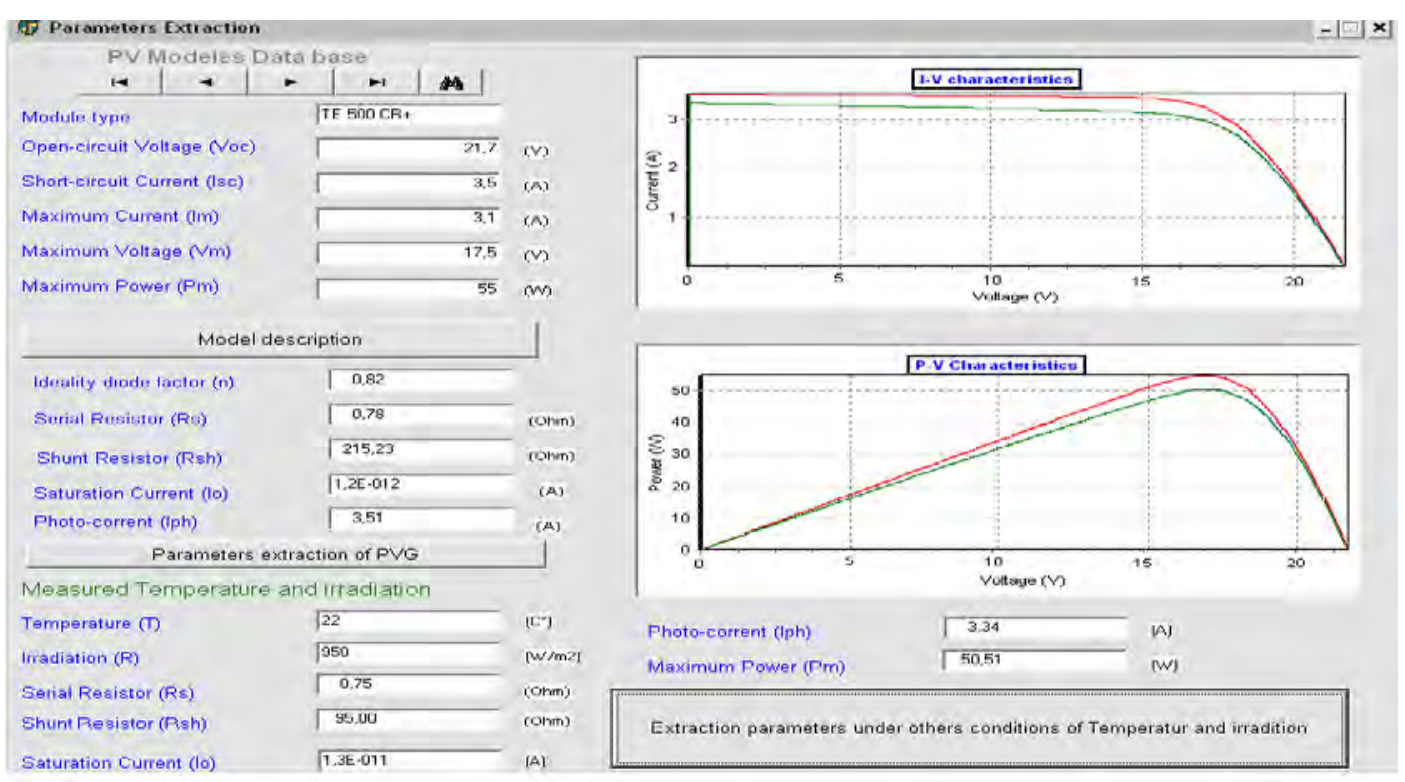

Fig.8: PVG parameter extraction from manufacture data in STC and from authors temperature and irradiation values.

\subsection{PVG parameter identification platform using correlation with measured characteristics}

After developing the data acquisition system for PVG characteristics measurements, we are very interested by the developing of software which permits the identification of PVG parameters in correlation with the measurements characteristics. The identification algorithm is based on the calculation of the correlation factor named " $\mathrm{R}^{2 \text { " }}$ between measurements and simulated characteristics. This coefficient is given by the equation number (3).

$$
R^{2}=1-\frac{\sum\left(X_{\text {exp }}-X_{\text {sim }}\right)^{2}}{\sum\left(X_{\text {exp }}-\overline{X_{\text {exp }}}\right)^{2}}
$$

The following figure shows this software. This software permits also the identification of the current and voltage coefficients of temperature.

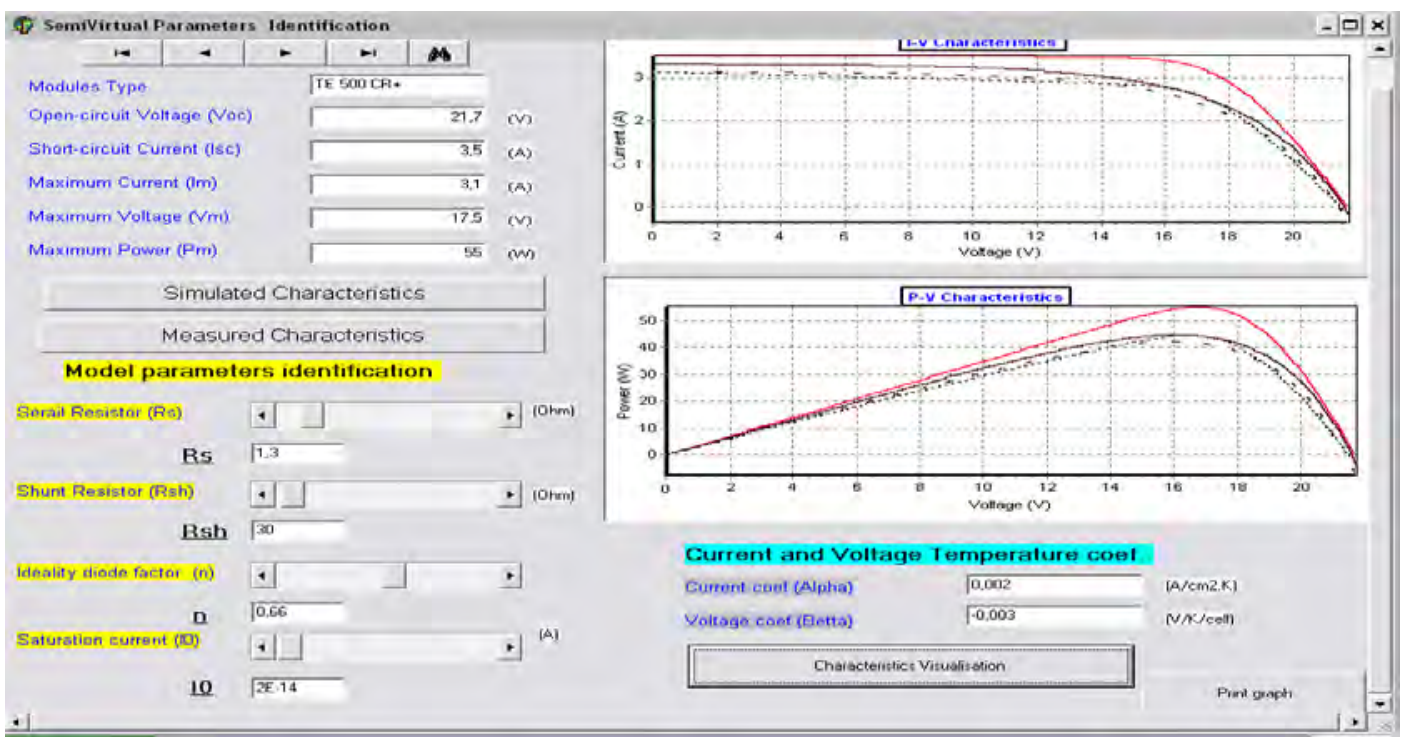

Fig.9: Software of PVG parameters identification using correlation between measurement and simulated characteristics. 


\section{Example for commercial PVG characterization}

This example is study the PV commercial module "TE500CR+". It is multi-crystalline technology [12]. The following figure, shows the I-V and P-V characteristics for the SNL, one diode model and experimental measurement at $\mathrm{T}=20^{\circ} \mathrm{C}, \mathrm{Ir}=820 \mathrm{~W} / \mathrm{m}^{2}$ and $\mathrm{Ws}=3.5 \mathrm{~m} / \mathrm{s}$.

Table 2: Results of TE $500 \mathrm{CR}+$ module characterization

\begin{tabular}{|c|c|c|c|c|c|c|c|c|c|c|c|c|c|c|}
\hline \multirow{2}{*}{\multicolumn{4}{|c|}{$\begin{array}{l}\text { Manufactures results } \\
\text { (STC conditions) }\end{array}$}} & \multicolumn{3}{|c|}{ Isc(A) } & \multicolumn{2}{|c|}{ Voc (V) } & \multicolumn{2}{|c|}{$\operatorname{Pm}(\mathrm{W})$} & \multicolumn{2}{|c|}{$\operatorname{Im}(\mathrm{A})$} & \multicolumn{2}{|c|}{$\mathrm{Vm}(\mathrm{V})$} \\
\hline & & & & \multicolumn{3}{|c|}{3,50} & \multicolumn{2}{|c|}{21.70} & \multicolumn{2}{|l|}{55} & \multicolumn{2}{|c|}{3,10} & \multicolumn{2}{|l|}{17,50} \\
\hline \multicolumn{2}{|c|}{$\begin{array}{l}\text { Real } \\
\text { Meteorological } \\
\text { data measurement }\end{array}$} & & del & Isc & & & Voc & $\begin{array}{l}\mathrm{E}_{\mathrm{Voc}} \\
(\%)\end{array}$ & $\mathrm{Pm}$ & $\begin{array}{l}\mathrm{E}_{\mathrm{Pm}} \\
(\%)\end{array}$ & $\operatorname{Im}$ & $\begin{array}{l}\mathrm{E}_{\mathrm{Im}} \\
(\%)\end{array}$ & $\mathrm{Vm}$ & $\begin{array}{l}\mathrm{E}_{\mathrm{Vm}} \\
(\%)\end{array}$ \\
\hline \multirow{3}{*}{\multicolumn{2}{|c|}{$\begin{array}{l}\mathrm{T}=20^{\circ} \mathrm{C} \\
\mathrm{Ir}=820 \mathrm{~W} / \mathrm{m}^{2} \\
W s=3.5 \mathrm{~m} / \mathrm{s}\end{array}$}} & & $\begin{array}{l}\text { easured } \\
\text { ults }\end{array}$ & \multicolumn{3}{|c|}{3.406} & \multicolumn{2}{|c|}{19.463} & \multicolumn{2}{|c|}{46.64} & \multicolumn{2}{|c|}{2.88} & \multicolumn{2}{|l|}{14.78} \\
\hline & & \multirow{2}{*}{\multicolumn{2}{|c|}{ RMSE }} & \multicolumn{9}{|c|}{ Measured results/ One diode model prediction } & \multicolumn{2}{|l|}{0,69} \\
\hline & & & & \multicolumn{9}{|c|}{$\begin{array}{llll}\begin{array}{l}\text { Measured } \\
\text { prediction }\end{array} & \text { results/ Sandia model app } \\
\end{array}$} & \multicolumn{2}{|l|}{0.63} \\
\hline \multirow{4}{*}{\multicolumn{2}{|c|}{ FF }} & \multicolumn{11}{|c|}{ Manufactures results (STC conditions) } & \multicolumn{2}{|l|}{0.72} \\
\hline & & \multicolumn{11}{|c|}{ Measured results } & \multicolumn{2}{|l|}{0.64} \\
\hline & & \multicolumn{11}{|c|}{ One diode model prediction } & \multicolumn{2}{|l|}{0.70} \\
\hline & & \multicolumn{11}{|c|}{ Sandia approximation model prediction } & \multicolumn{2}{|l|}{0.67} \\
\hline \multicolumn{15}{|c|}{ One-diode PVG model parameters identification } \\
\hline \multirow[t]{3}{*}{$\begin{array}{l}\text { TE } 500 \mathrm{CR}+ \\
\text { module }\end{array}$} & \multicolumn{8}{|c|}{$\begin{array}{l}\text { Model parameters identification using } \\
\text { correlation with measured values with } \mathrm{R}^{2}=0,98\end{array}$} & $\begin{array}{l}\text { Mod } \\
\text { mant }\end{array}$ & $\begin{array}{l}\text { l paran } \\
\text { facture }\end{array}$ & daters & extracte & d using & \\
\hline & $\mathrm{I}_{\mathrm{ph}}$ & & $\mathrm{I}_{0}(\mathrm{~A})$ & $\mathrm{R}_{\mathrm{s}}($ & & & & $\mathrm{n}$ & $\mathrm{I}_{\mathrm{ph}}(A$ & $\mathrm{I}_{0}(\mathrm{~A})$ & & $\underline{R_{\mathrm{s}}(\Omega)}$ & $\mathrm{R}_{\mathrm{sh}}(\Omega)$ & $\mathrm{n}$ \\
\hline & 3.1 & & $2 \mathrm{e}-14$ & 1,3 & & 30 & & 0.66 & 3.51 & $1.2 \mathrm{e}-12$ & & .78 & 215,23 & 0.82 \\
\hline
\end{tabular}
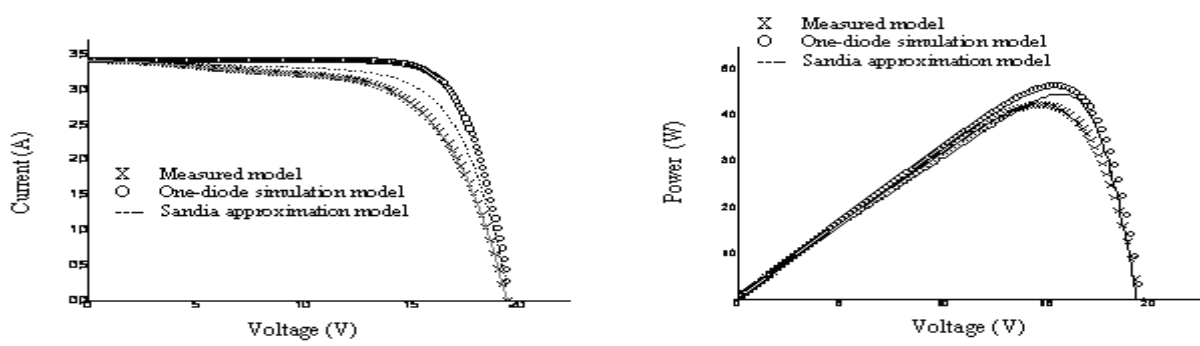

Fig.10: $I-V$ and P-V TE500CR+ module characteristics comparison between Sandia approximations, One-diode estimated model and experimental results.

\section{Conclusion}

This work described the functioning of the designed semi-virtual laboratory for PVG performance characterization methodology. This laboratory based on the comparison between the predicted models results and experimental ones. I-V and P-V, characteristics are obtained and compared, in one hand. In the other hand the PVG parameters are obtained using predict models and experimental results for real and estimated meteorological data. The present example for measurement and modeling applied for the TE500CR + modules can be used for characterized different PV commercial modules. The final objectives is to duplicated this results and choose modules gives good response when they are introducing in the PV installation and gives either a best installation dimensioning. In perspectives of this research is to introduce other PVG models in this semi-virtual laboratory and its compared with the studied ones

\section{References}

[1] Test Method for Photovoltaic Module Power Rating, FSEC Standard 202-05, Research institute of the university of central Florida, May 2005 
[2] David L. King, William E. Boyson and al, "Application and Validation of a New PV Performance Characterization Method", $26^{\text {th }}$ IEEE Photovoltaic Specialists Conference, September 29 October 3, 1997, Anaheim, California.

[3] W. Durisch ,J. Urban and G. Smestad, "Characterisation of solar cells and modules under actual operating conditions" California 93955-8001, California, U.S.A. WREC 1996

[4] Ali Nacer celik and Nasir Acikgoz, "Modeling and experimental verification of the operating current of mono-crystalline photovoltaic modules using four and five parameter models”, Elsevier, Applied energy pp 84 (2007)1-15.

[5] D. S. H. Chan, J. R. Philips and J. C. H. Phang, "A comparative study of extraction methods for solar cell model parameters", Solid-State Electronics Vol. 29, No. 3. pp. 329$337,1986$.

[6] D. L. King et al, Photovoltaic system performance characterization methodologies, NREL/CD-520-33586, 543-546.

[7] A. Hunter Fanney, and al, «Comparison of Photovoltaic Module Performance Measurements". 152 / Vol. 128, MAY 2006 Copyright (C) 2006by ASME Transactions of the ASME

[8] D.L. King, J.A. Kratochvil, W.E. Boyson, and W.I. Bower, "Field experience with a new performance characterization procedure for photovoltaic arrays", $2^{\text {nd }}$ World Conference and Exhibition on Photovoltaic Solar Energy Conversion, 6-10 July 1998, Vienna, Austria.

[9] http://www.sandia.gov/pv/

[10]Hocine Belmili, Salah Med Aitcheikh, Mourad Haddadi, Cherif Larbas "Design and development of a data acquisition system for photovoltaic modules characterization" Elsevier Renewable energy 35(2010)1484-1492.

[11]Piedallu, C. and Gégout, J.C. "Multiscale computation of solar radiation for predictive vegetation Modeling". Annals of Forest Science, 64: 899-909. 2007.

[12] TE $500 \mathrm{CR}+$ Modules. www.total-energie.com. 